\title{
Targeted Genomic Sequencing Reveals Different Evolutionary Patterns Between Locally and Distally Recurrent Glioblastomas
}

\author{
NARA YOON ${ }^{*}$, HYUN-SOO KIM $^{2 *}$, JUNG WHEE LEE $^{3}$, EUI-JIN LEE ${ }^{4}$, LEE-SO MAENG $^{1}$ and WAN SOO YOON 5 \\ ${ }^{1}$ Department of Pathology, Incheon St. Mary's Hospital, College of Medicine, \\ The Catholic University of Korea, Incheon, Republic of Korea; \\ ${ }^{2}$ Department of Pathology and Translational Genomics, Samsung Medical Center, \\ Sungkyunkwan University School of Medicine, Seoul, Republic of Korea; \\ ${ }^{3}$ Department of Radiology, Incheon St. Mary's Hospital, College of Medicine, \\ The Catholic University of Korea, Incheon, Republic of Korea; \\ ${ }^{4}$ Institute of Catholic Integrative Medicine, Incheon St. Mary's Hospital, \\ College of Medicine, The Catholic University of Korea, Incheon, Republic of Korea; \\ ${ }^{5}$ Department of Neurosurgery, Incheon St. Mary's Hospital, College of Medicine, \\ The Catholic University of Korea, Incheon, Republic of Korea
}

\begin{abstract}
Background/Aim: Glioblastoma is the most malignant form of astrocytoma. The purpose of this study was to analyze the genetic characteristics of primary and recurrent glioblastomas using targeted sequencing and investigate the differences in mutational profiles between the locations of tumor recurrence. Materials and Methods: Fourteen glioblastoma patients who developed local $(n=10)$ or distal $(n=4)$ recurrence were included in the study. Targeted sequencing analysis was performed using the primary ( $n=14)$ and corresponding recurrent $(n=14)$ tumor tissue samples. Results: The local and distal recurrence groups showed different genetic evolutionary patterns. Most of the locally recurrent glioblastomas demonstrated concordant mutational profiles between the primary and recurrent tumors, suggesting a linear evolution. In contrast, all cases of distally recurrent
\end{abstract}

This article is freely accessible online.

*These Authors contributed equally to this study.

Correspondence to: Wan Soo Yoon, Department of Neurosurgery, Incheon St. Mary's Hospital, College of Medicine, The Catholic University of Korea, 56, Dongsu-ro, Bupyeong-gu, Incheon 21431, Republic of Korea. Tel: +82 322805486, Fax: +82 322805500, email: yowas@catholic.ac.kr; Lee-So Maeng, Department of Pathology, Incheon St. Mary's Hospital, College of Medicine, The Catholic University of Korea, 56, Dongsu-ro, Bupyeong-gu, Incheon 21431, Republic of Korea. Tel: +82 322805519, Fax: +82 322805500, e-mail: mls1004@ catholic.ac.kr

Key Words: Brain, glioblastoma, recurrence, evolutionary pattern, targeted sequencing. glioblastomas showed changes in mutational profiles with newly acquired mutations when compared to the corresponding primary tumors, suggesting a branching evolution. Conclusion: Locally and distally recurrent glioblastomas exhibit different evolutionary patterns.

Glioblastoma is the most common malignant tumor of the central nervous system (1-9). The current standard treatment for glioblastoma involves surgical resection, followed by concurrent chemoradiation therapy and adjuvant chemotherapy using temozolomide (8-12). Due to the invasive nature of glioblastoma, surgical resection rarely eliminates all tumor cells, and postoperative treatment is usually necessary to prevent disease recurrence. Despite the advances made in therapeutic strategies, the prognosis of patients with glioblastoma remains very poor, with an average survival of 15 months (13-15) and disease recurrence being the major cause of mortality (16-18). Recurrent glioblastomas tend to be more invasive and resistant to chemotherapy than primary tumors. An understanding of the genetic characteristics of recurrent glioblastoma is crucial for identifying potential targets for drug discovery, stratifying patients for diagnosis, and optimizing an effective treatment strategy.

Previous studies have shown the molecular features of recurrent glioblastomas. In particular, the mutational profiles observed in recurrent glioblastomas were compared to those of the corresponding primary tumors (19-21). However, there is a lack of studies exploring the differences in mutational profiles between recurrent glioblastomas at different sites $(21,22)$. In this study, we investigated the mutational profiles of primary and recurrent glioblastomas using 
targeted sequencing analysis. We then compared the sequencing results between the locations of recurrent tumors, i.e. local and distal recurrences. We anticipate that our comprehensive analyses will extend the current knowledge in relation to the clonal evolution of recurrent glioblastoma by describing its genetic characteristics obtained from targeted sequencing analysis.

\section{Materials and Methods}

Case selection. This study (OC18TESI0052) was reviewed and approved by the Institutional Review Board of Incheon St. Mary's Hospital. Fourteen patients with glioblastoma were included in this study. Twenty-eight tumor tissue samples, including the primary $(n=14)$ and corresponding recurrent $(n=14)$ glioblastomas, were obtained from the surgical pathology archives of the Incheon St. Mary's Hospital. Ten of the fourteen patients developed recurrence at the same site or a location closely adjacent to that of the primary tumor and were classified as the local recurrence group (Figure 1AB). The remaining four patients developed recurrence at different anatomical locations from that of the primary tumor and were classified as the distal recurrence group (Figure 1C-D). Clinical information was obtained from the electronic medical record system. All patients received postoperative concurrent chemoradiation therapy, with subsequent adjuvant chemotherapy using temozolomide. None of the patients received preoperative radiation therapy or chemotherapy.

Pathological examination. Two board-certified pathologists specializing in neuro-oncology reviewed all available hematoxylin and eosin-stained slides using light microscopy and analyzed the following histological characteristics of primary and recurrent glioblastoma tissues: cellularity, nuclear pleomorphism, microvascular proliferation, and coagulative tumor cell necrosis (23). They chose representative slides for each case to perform targeted sequencing.

Targeted sequencing. The tissue samples from tumors were obtained by manual microdissection and were then subjected to DNA and RNA extraction for library preparation. The normal tissues of each case were obtained from the adjacent non-neoplastic areas. DNA and RNA were isolated from $10-\mu \mathrm{m}$ thick slices of formalin-fixed, paraffin-embedded tissues using a sterile 26-gauge needle and RecoverAll $^{\mathrm{TM}}$ Multi-Sample DNA/RNA Isolation Workflow (Thermo Fisher Scientific, Waltham, MA, USA). DNA and RNA were quantified using the Qubit 2.0 Fluorometer (Thermo Fisher Scientific). DNA and RNA libraries were prepared as previously described (24-35). These DNA libraries were generated from $20 \mathrm{ng}$ of DNA per sample using an Ion AmpliSeq Library Kit 2.0 (Thermo Fisher Scientific) and the Oncomine Comprehensive Assay v1 (OCA v1) panel (Thermo Fisher Scientific). RNA libraries were generated from $15 \mathrm{ng}$ of RNA per sample using Ion AmpliSeq RNA Library Kit (Thermo Fisher Scientific) and OCA v1 panel. Libraries were quantified using the Ion Library Universal Quantification Kit (Thermo Fisher Scientific). The OCA v1 panel (Thermo Fisher Scientific) included 143 genes, of which 73 oncogenes were examined for mutational hotspots, and 26 tumor suppressor genes were examined for the presence of all of the exons. The panel was used to detect copy number alterations (CNAs) in 49 genes and fusion drivers in 22 genes. The gene list is available at https://www.thermofisher.com/kr/ko/home/clinical/preclinicalcompanion-diagnostic-development/oncomine-oncology/oncominecancer-research-panel-workflow.html. A pool of DNA library (60 $\mathrm{pmol} / \mathrm{l}$ ) was used to prepare a template Ion Sphere Particle (Thermo Fisher Scientific). DNA sequencing was performed using the Ion 540 Kit-Chef (Thermo Fisher Scientific) and Ion S5 system (Thermo Fisher Scientific). Sequencing data of approximately 200 bp reads were generated after 500 flow runs.

Analysis of the sequencing data was performed using the Torrent Suite Software v5.2.2 (Thermo Fisher Scientific). This workflow was created by adding a custom hotspot Browser Extensible Data file to report mutations of interest and a custom CNA baseline (described below) using the manufacturer's default workflow, as described previously $(24,25,35)$. The pipeline used included signaling processing, base calling, quality score assignment, adapter trimming, read mapping to the human genome assembly GRCh37, quality control of mapping, coverage analysis with downsampling, and variant calling. The identification of variants was performed using the Torrent Variant Caller plug-in and Ion Reporter Software v5.2 (Thermo Fisher Scientific). Coverage maps were generated using the Coverage Analysis plug-in (Thermo Fisher Scientific). Additionally, ANNOVAR (http://annovar.openbioinformatics.org/) was used for functional annotation of identified single nucleotide variants (SNVs) to investigate their genomic locations (36). To eliminate artifacts, sequence data were visually confirmed using the Integrative Genomics Viewer software (Broad Institute, Cambridge, MA, USA). This workflow was able to report SNVs and insertions/deletions (indels) in as low as $1 \%$ of the variant allele fraction. Based on the results of a feasibility study, the variant allele fraction threshold was established at $2 \%$. Copy number analysis was performed using the copy number module within the aforementioned workflow of the Ion Reporter Software v5.2. Copy numbers of four or greater were considered concordant if the orthogonal assay also reported a copy number of four or greater for target genes. Gene fusions were detected using the fusion detection module within the Ion Reporter Software (Thermo Fisher Scientific) workflow. This pipeline only reported fusions that were annotated previously, as defined in a reference file preloaded into the workflow $(24,25,35)$.

\section{Results}

Histological features of primary and recurrent glioblastomas. All examined tumor tissue samples displayed the typical histological features of high-grade astrocytoma (hypercellularity, severe nuclear pleomorphism with anaplastic and bizarre nuclei and occasional multinucleation, and increased mitotic activity with atypical mitotic figures), coagulative tumor cell necrosis, and microvascular proliferation (capillary wall thickening due to endothelial cell hyperplasia and hypertrophy or formation of multiple lumina). None of the cases showed foci of giant cell glioblastomas, gliosarcomas, or epithelioid glioblastomas. Representative photomicrographs showing the histological features of glioblastomas are shown in Figure 2. No significant morphological difference was observed between the primary (Figure 2A) and recurrent (Figure 2B) glioblastomas. Additionally, there was no significant difference in the histological features observed between the local and distal recurrence groups. 

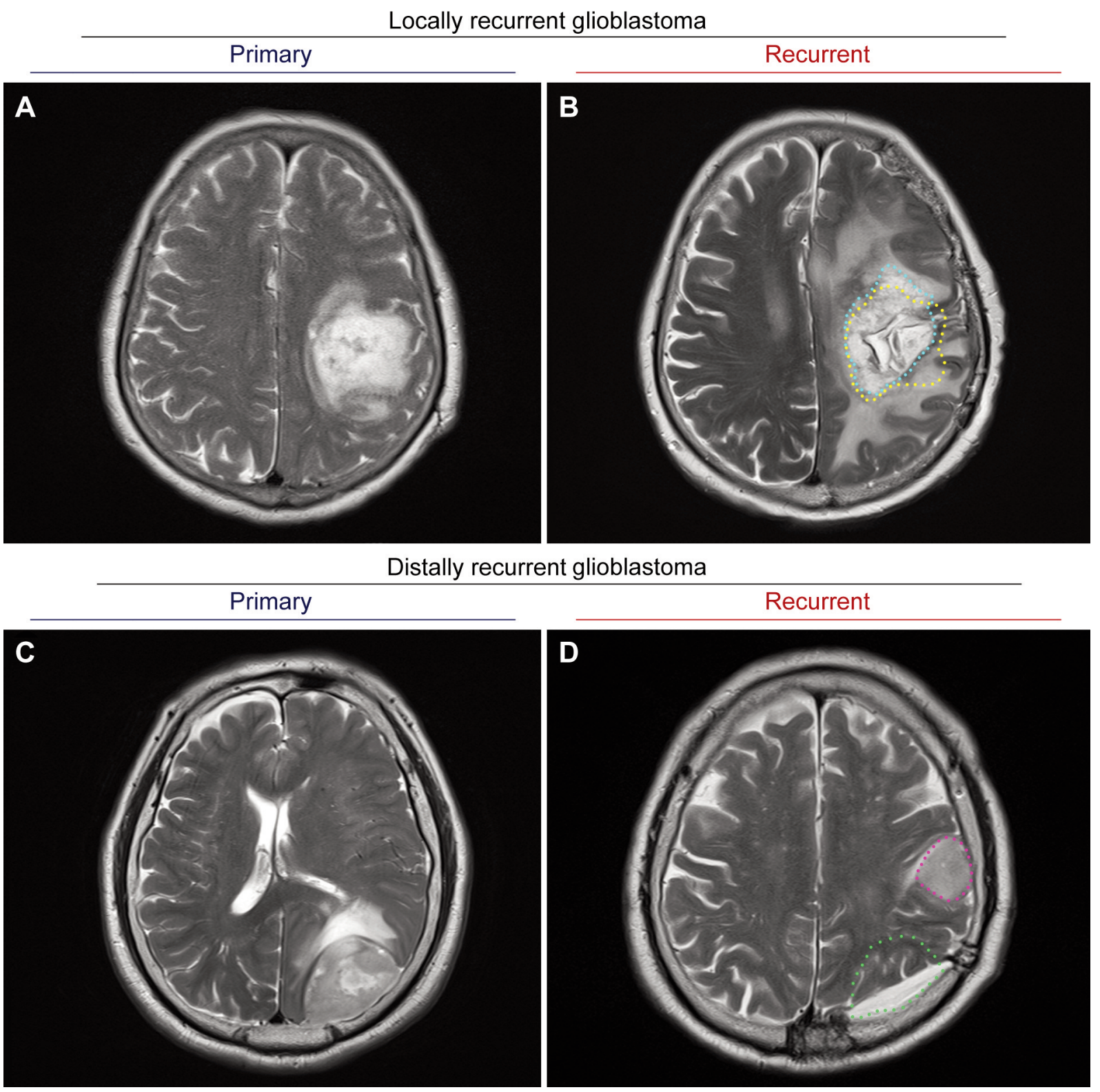

Figure 1. Representative magnetic resonance images showing the locations of recurrent glioblastomas. (A-B) Locally recurrent glioblastoma. The location of primary tumor (outlined by yellow dots) is nearly identical to that of the recurrent tumor (blue dots). (C-D) Distally recurrent glioblastoma. The location of recurrent tumor (purple dots) is different from that of primary tumor (green dots).

Targeted sequencing results. Sequence data were successfully obtained from all tissue samples. Figure 3 summarizes the targeted sequencing results. In 9 cases of primary glioblastoma, $19 \mathrm{SNV}$ s/indels were identified in 7 genes, and they consisted of 14 missense mutations, 1 frameshift deletion mutation, and 4 nonsense mutations. The most commonly detected SNV/indel in the sequences of primary glioblastoma samples was tumor protein 53 (TP53) mutation (7/14); these mutations included p.Cys135Tyr (1/7), p.Arg158His (1/7), p.Tyr220Cys (1/7),
p.Arg267Trp (1/7), p.Arg273Cys (1/7), p.Pro278Thr (1/7), and p.Asp281Tyr (1/7). The second most common detected SNV/indel in sequences of primary glioblastoma samples was the phosphatase and tensin homolog deleted in chromosome 10 (PTEN) mutation (5/14); these mutations included p.Tyr68Ter (1/5), p.Gln110Ter (1/5), p.Arg130Gly (1/5), p.Gly132Arg $(1 / 5)$, and p.Lys254fs (1/5). Additionally, mutations in neurofibromin $1(N F 1 ; 1 / 14)$, platelet-derived growth factor receptor-alpha (PDGFRA), adenomatous polyposis coli (APC), 


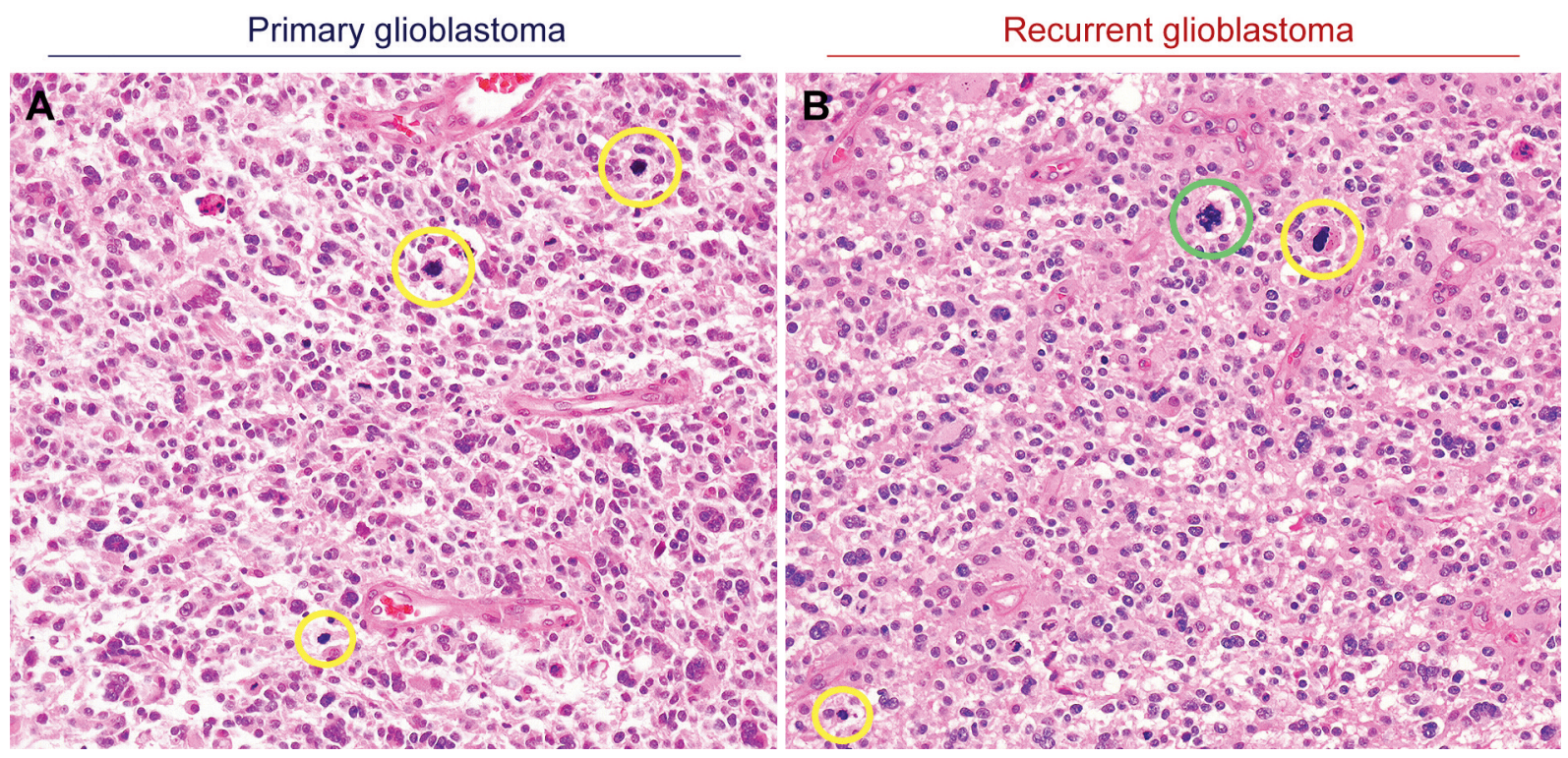

Figure 2. Representative photomicrographs of glioblastoma showing histological concordance between primary and recurrent tumors. No significant histological difference is observed between primary and recurrent glioblastomas. Yellow and green circles indicate typical and atypical mitotic figures, respectively. Staining method, hematoxylin and eosin staining. Original magnification of A and B, 200x.

and v-raf murine sarcoma viral oncogene homolog $\mathrm{B} 1(B R A F$; $1 / 14)$, were detected in four different primary glioblastomas. Ten primary glioblastomas harbored CNAs, that were detected in four genomic regions and included seven gains and seven losses. The most common CNAs in primary glioblastomas were epidermal growth factor receptor $(E G F R)$ amplification $(6 / 14)$ and cyclin-dependent kinase inhibitor 2A (CDKN2A) deletion (6/14). Additionally, an NFI deletion (1/14) and PDGFRA amplification (1/14) were detected in two cases of primary glioblastoma.

Ten recurrent glioblastomas harbored $\mathrm{SNV}$ s/indels, which consisted of 14 missense mutations, 1 frameshift deletion mutation, and 1 nonsense mutation. Seven recurrent glioblastoma tissue samples most commonly harbored TP53 mutations, all of which showed the same mutation type as their corresponding primary tumor tissue samples. The second most common SNVs/indels in the DNA of recurrent glioblastoma samples were PTEN (3/14) and EGFR mutations (3/14). Mutations in the F-box and WD repeat domain-containing 7 (FBXW7; p.Arg505His) and EGFR (p.Pro596Leu and p.Gly598Val) that were not identified in any of the primary glioblastoma cases were detected in three different recurrent glioblastoma samples. In eight cases of recurrent glioblastoma, CNAs were detected in four genomic regions and included six gains and six losses. The most common CNAs in recurrent glioblastoma were $E G F R$ amplification (5/14) and $C D K N 2 A$ deletion (5/14). CDKN2A deletion and PDGFRA amplification, both of which were not observed in any of the primary glioblastoma cases, were detected in one recurrent glioblastoma case. No gene fusion was detected, and no pathogenic mutation was identified in the normal brain tissue.

Differences in mutational profiles between the locations of tumor recurrence. We compared the targeted sequencing results between the local and distal recurrence groups (Figure 4). The location of SNVs/indels and type of CNAs were completely concordant in 6 of the 10 locally recurrent glioblastoma cases (cases 1-6; Table I). In contrast, four cases (cases 7-10; Table II) displayed mutations in the primary tumors, including nonsense PTEN mutation, CDKN2A deletion, and amplifications of EGFR and PDGFRA, all of which were not detected in the recurrent tumors. Two of the four cases showed a partial concordance in the missense TP53 mutation (case 7) and NF1 deletion (case 8), respectively.

None of the distally recurrent glioblastoma cases (cases 11-14) showed concordance in the mutational profiles when compared to primary glioblastoma cases. Acquired mutations were detected in all cases of distally recurrent glioblastoma and included missense $F B X W 7$ mutation (case 12), missense EGFR mutations (cases 13 and 14), CDKN2A deletion (case 11), and PDGFRA amplification (case 11). In three cases, mutations observed in the primary tumors, including mutations or CNAs in CDKN2A, EGFR, $P D G F R A, P T E N$, and $A P C$, were not detected in the recurrent tumors. 


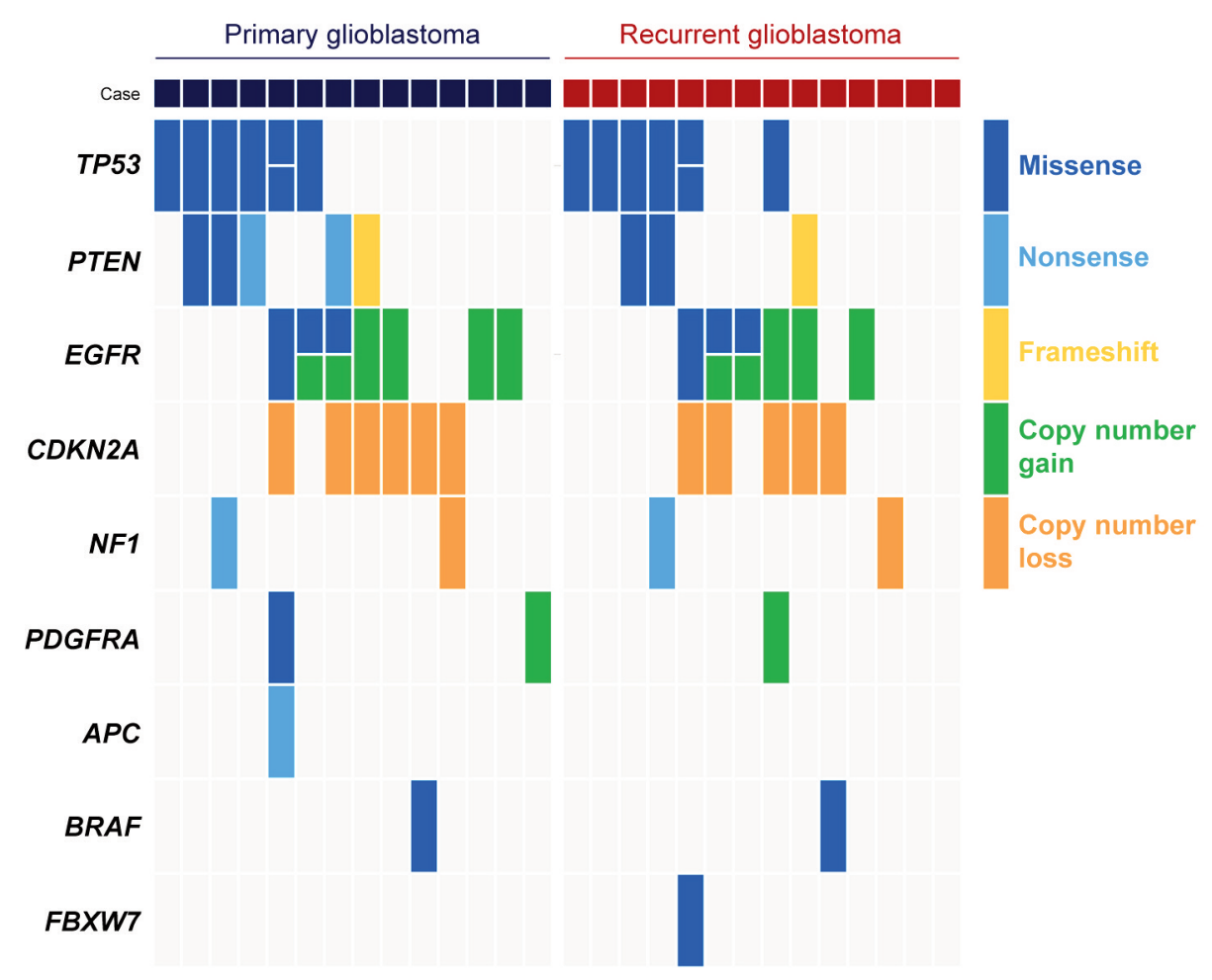

Figure 3. Targeted sequencing results of the primary (n=14) and corresponding recurrent (n=14) glioblastomas.

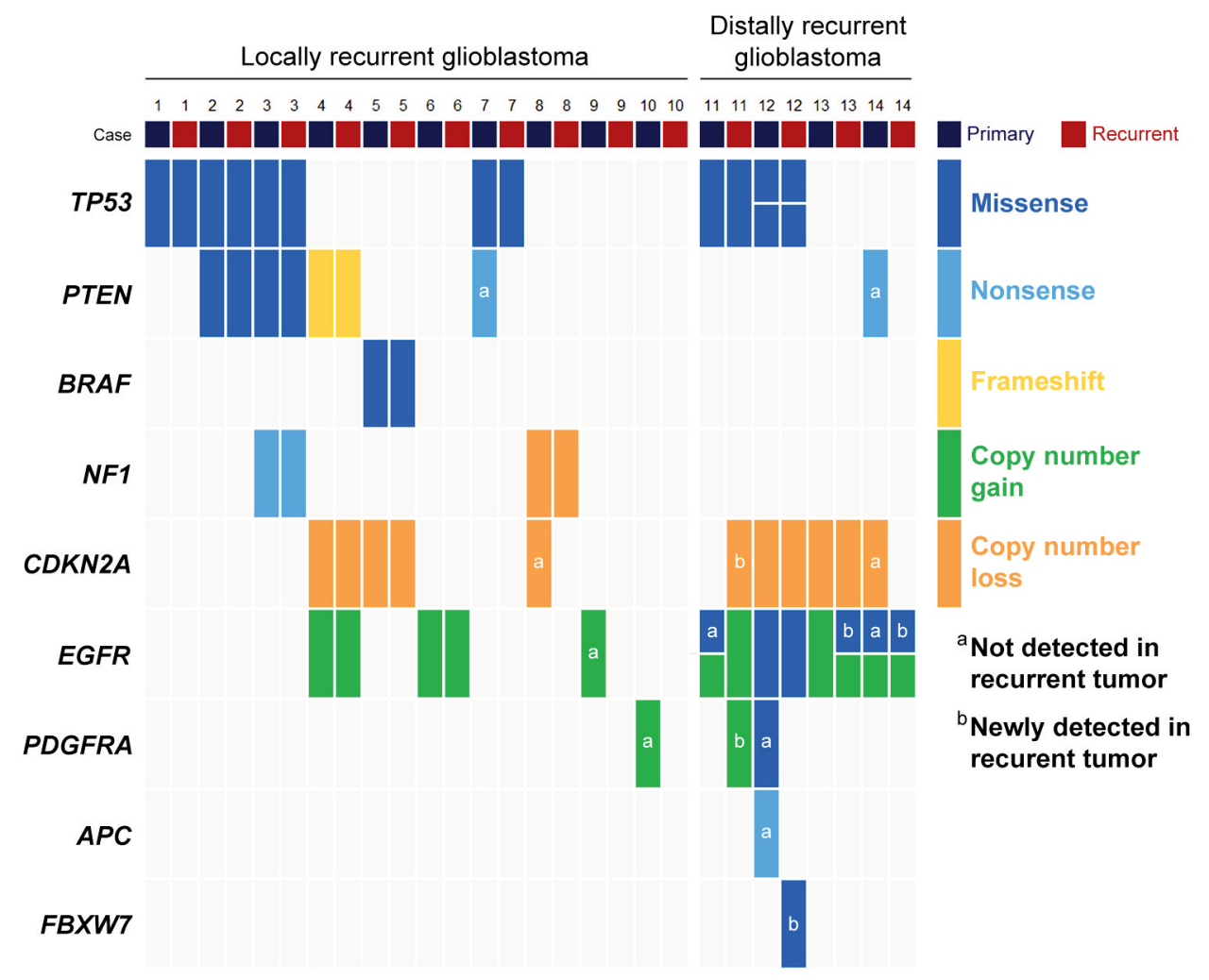

Figure 4. Comparison of targeted sequencing results between locally $(n=10)$ and distally $(n=4)$ recurrent glioblastomas. 
Table I. Targeted sequencing results of 10 cases of locally recurrent glioblastoma.

\begin{tabular}{|c|c|c|c|c|c|c|c|}
\hline $\begin{array}{l}\text { Case } \\
\text { no. }\end{array}$ & $\begin{array}{l}\text { Sample } \\
\text { type }\end{array}$ & Gene & $\begin{array}{l}\text { Mutation } \\
\text { type }\end{array}$ & $\begin{array}{l}\text { Nucleotide } \\
\text { change }\end{array}$ & $\begin{array}{l}\text { Amino acid } \\
\text { change }\end{array}$ & $\begin{array}{c}\text { Allele } \\
\text { frequency }\end{array}$ & $\begin{array}{l}\text { Copy } \\
\text { number }\end{array}$ \\
\hline \multirow[t]{2}{*}{1} & Primary & TP53 & Missense & c. $799 \mathrm{C}>\mathrm{T}$ & p.Arg267Trp & $25.0 \%$ & \\
\hline & Recurrent & TP53 & Missense & c. $799 \mathrm{C}>\mathrm{T}$ & p.Arg267Trp & $39.3 \%$ & \\
\hline \multirow[t]{4}{*}{2} & Primary & TP53 & Missense & c. $404 \mathrm{G}>\mathrm{A}$ & p.Cys135Tyr & $72.8 \%$ & \\
\hline & & PTEN & Missense & c. $388 \mathrm{C}>\mathrm{G}$ & p.Arg130Gly & $32.0 \%$ & \\
\hline & Recurrent & TP53 & Missense & c. $404 \mathrm{G}>\mathrm{A}$ & p.Cys135Tyr & $13.0 \%$ & \\
\hline & & PTEN & Missense & c. $388 \mathrm{C}>\mathrm{G}$ & p.Arg130Gly & $2.8 \%$ & \\
\hline \multirow[t]{6}{*}{3} & Primary & TP53 & Missense & c. $841 \mathrm{G}>\mathrm{T}$ & p.Asp281Tyr & $61.3 \%$ & \\
\hline & & PTEN & Missense & c. $394 \mathrm{G}>\mathrm{C}$ & p.Gly132Arg & $56.3 \%$ & \\
\hline & & $N F 1$ & Nonsense & c. $.5959 \mathrm{C}>\mathrm{T}$ & p.Gln1987Ter & $60.4 \%$ & \\
\hline & Recurrent & TP53 & Missense & c. $841 \mathrm{G}>\mathrm{T}$ & p.Asp281Tyr & $42.4 \%$ & \\
\hline & & PTEN & Missense & c. $394 \mathrm{G}>\mathrm{C}$ & p.Gly132Arg & $39.7 \%$ & \\
\hline & & $N F 1$ & Nonsense & c. $5959 \mathrm{C}>\mathrm{T}$ & p.Gln1987Ter & $39.6 \%$ & \\
\hline \multirow[t]{6}{*}{4} & Primary & PTEN & Frameshift & c.761_765delAAGTA & p.Lys $254 \mathrm{fs}$ & $65.1 \%$ & \\
\hline & & $E G F R$ & CNA & & & & 98.26 (amplification) \\
\hline & & $C D K N 2 A$ & CNA & & & & 0 (deletion) \\
\hline & Recurrent & PTEN & Frameshift & c.761_765delAAGTA & p.Lys $254 \mathrm{fs}$ & $35.7 \%$ & \\
\hline & & $E G F R$ & CNA & & & & 71.59 (amplification) \\
\hline & & $C D K N 2 A$ & CNA & & & & 0.8 (deletion) \\
\hline \multirow[t]{4}{*}{5} & Primary & BRAF & Missense & c. $1799 \mathrm{~T}>\mathrm{A}$ & p.Val600Glu & $41.0 \%$ & \\
\hline & & $C D K N 2 A$ & CNA & & & & 0.34 (deletion) \\
\hline & Recurrent & BRAF & Missense & c. $1799 \mathrm{~T}>\mathrm{A}$ & p.Val600Glu & $50.6 \%$ & \\
\hline & & $C D K N 2 A$ & CNA & & & & 0.21 (deletion) \\
\hline \multirow[t]{2}{*}{6} & Primary & $E G F R$ & $\mathrm{CNA}$ & & & & 18.91 (amplification) \\
\hline & Recurrent & $E G F R$ & CNA & & & & 43.35 (amplification) \\
\hline \multirow[t]{3}{*}{7} & Primary & TP53 & Missense & c. $817 \mathrm{C}>\mathrm{T}$ & p.Arg273Cys & $56.1 \%$ & \\
\hline & & PTEN & Nonsense & c. $328 \mathrm{C}>\mathrm{T}$ & p.Gln110Ter & $36.7 \%$ & \\
\hline & Recurrent & TP53 & Missense & c. $817 \mathrm{C}>\mathrm{T}$ & p.Arg273Cys & $40.5 \%$ & \\
\hline \multirow[t]{3}{*}{8} & Primary & NF1 & CNA & & & & 0 (deletion) \\
\hline & & $C D K N 2 A$ & CNA & & & & 0 (deletion) \\
\hline & Recurrent & NF1 & $\mathrm{CNA}$ & & & & 0 (deletion) \\
\hline \multirow[t]{2}{*}{9} & Primary & $E G F R$ & $\mathrm{CNA}$ & & & & 24.81 (amplification) \\
\hline & Recurrent & Not detected & Not applicable & & & & \\
\hline \multirow[t]{2}{*}{10} & Primary & PDGFRA & CNA & & & & 27.25 (amplification) \\
\hline & Recurrent & Not detected & Not applicable & & & & \\
\hline
\end{tabular}

$B R A F$ : v-raf murine sarcoma viral oncogene homolog B1, CDKN2A: cyclin-dependent kinase inhibitor 2A, CNA: copy number alteration, EGFR: epidermal growth factor receptor, $N F 1$ : neurofibromin 1, PDGFRA: platelet-derived growth factor receptor A, PTEN: phosphatase and tensin homolog deleted on chromosome 10, TP53: tumor protein 53 .

\section{Discussion}

Previous studies have documented the genetic alterations in primary glioblastomas and their corresponding recurrent glioblastomas and have suggested two different patterns of evolution (18, 21, 37-39). The first pattern is a linear evolution demonstrating a high concordance between the mutation patterns of primary and recurrent tumors, suggestive of late evolutionary divergence. The second pattern is a branching evolution showing relatively distinct mutation patterns between the primary and recurrent tumors, suggestive of an early separation in the lineage. In a previous study reporting the genomic profile of glioblastomas (21), distally recurrent glioblastomas shared only a fraction of the primary tumor mutations, indicative of branching evolution. In contrast, locally recurrent glioblastomas shared the majority of mutations harbored by the primary tumors, indicating a linear evolution. These data suggest that the location of recurrent tumors may help predict the genomic evolutionary patterns in glioblastomas. In this study, the recurrent glioblastomas showed two different evolutionary patterns according to their location of recurrence. Eight of the ten local recurrent glioblastomas showed a linear evolutionary pattern, demonstrating a complete or partial concordance in the mutational profiles between primary and recurrent tumors, without any acquired pathogenic mutation. Four distal recurrent glioblastomas showed branching evolutionary patterns with changes in the mutational profiles between the primary and recurrent tumors, including losing and 
Yoon et al: Targeted Sequencing of Locally and Distally Recurrent Glioblastomas

Table II. Targeted sequencing results of four cases of distally recurrent glioblastoma.

\begin{tabular}{|c|c|c|c|c|c|c|c|}
\hline $\begin{array}{l}\text { Case } \\
\text { no. }\end{array}$ & $\begin{array}{l}\text { Sample } \\
\text { type }\end{array}$ & Gene & $\begin{array}{l}\text { Mutation } \\
\text { type }\end{array}$ & $\begin{array}{l}\text { Nucleotide } \\
\text { change }\end{array}$ & $\begin{array}{l}\text { Amino acid } \\
\text { change }\end{array}$ & $\begin{array}{c}\text { Allele } \\
\text { frequency }\end{array}$ & $\begin{array}{l}\text { Copy } \\
\text { number }\end{array}$ \\
\hline \multirow[t]{7}{*}{11} & \multirow[t]{3}{*}{ Primary } & TP53 & Missense & c. $659 \mathrm{~A}>\mathrm{G}$ & p.Tyr220Cys & $67.0 \%$ & \\
\hline & & $E G F R$ & Missense & c. $664 \mathrm{C}>\mathrm{T}$ & p.Arg222Cys & $25.0 \%$ & \\
\hline & & $E G F R$ & CNA & & & & 27.97 (amplification) \\
\hline & \multirow[t]{4}{*}{ Recurrent } & TP53 & Missense & c. $659 \mathrm{~A}>\mathrm{G}$ & p.Tyr220Cys & $91.0 \%$ & \\
\hline & & EGFR & CNA & & & & 107.83 (amplification) \\
\hline & & $C D K N 2 A$ & CNA & & & & 0 (deletion) \\
\hline & & PDGFRA & CNA & & & & 6.09 (amplification) \\
\hline \multirow[t]{11}{*}{12} & \multirow[t]{6}{*}{ Primary } & TP53 & Missense & c. $832 \mathrm{C}>\mathrm{A}$ & p.Pro278Thr & $47.2 \%$ & \\
\hline & & TP53 & Missense & c. $473 \mathrm{G}>\mathrm{A}$ & p.Arg158His & $42.9 \%$ & \\
\hline & & $E G F R$ & Missense & c. $2029 \mathrm{C}>\mathrm{T}$ & p.Arg677Cys & $51.3 \%$ & \\
\hline & & PDGFRA & Missense & c. $2524 \mathrm{G}>\mathrm{T}$ & p.Asp842Tyr & $36.9 \%$ & \\
\hline & & $A P C$ & Nonsense & c. $8446 \mathrm{C}>\mathrm{T}$ & p.Arg2816Ter & $38.6 \%$ & \\
\hline & & $C D K N 2 A$ & CNA & & & & 0 (deletion) \\
\hline & \multirow[t]{5}{*}{ Recurrent } & TP53 & Missense & c. $832 \mathrm{C}>\mathrm{A}$ & p.Pro278Thr & $48.1 \%$ & \\
\hline & & TP53 & Missense & c. $473 \mathrm{G}>\mathrm{A}$ & p.Arg158His & $45.1 \%$ & \\
\hline & & $E G F R$ & Missense & c. $2029 \mathrm{C}>\mathrm{T}$ & p.Arg677Cys & $51.0 \%$ & \\
\hline & & FBXW7 & Missense & c. $1514 \mathrm{G}>\mathrm{A}$ & p.Arg505His & $43.0 \%$ & \\
\hline & & $C D K N 2 A$ & CNA & & & & 0.07 (deletion) \\
\hline \multirow[t]{5}{*}{13} & \multirow[t]{2}{*}{ Primary } & $E G F R$ & CNA & & & & 128.13 (amplification) \\
\hline & & $C D K N 2 A$ & CNA & & & & 0.04 (deletion) \\
\hline & \multirow[t]{3}{*}{ Recurrent } & $E G F R$ & Missense & c. $1787 \mathrm{C}>\mathrm{T}$ & p.Pro596Leu & $92.1 \%$ & \\
\hline & & $E G F R$ & CNA & & & & 36.53 (amplification) \\
\hline & & $C D K N 2 A$ & CNA & & & & 0.98 (deletion) \\
\hline \multirow[t]{6}{*}{14} & \multirow[t]{4}{*}{ Primary } & PTEN & Nonsense & c. $204 \mathrm{C}>\mathrm{A}$ & p.Tyr68Ter & $46.3 \%$ & \\
\hline & & $E G F R$ & Missense & c. $2369 \mathrm{C}>\mathrm{T}$ & p.Thr790Met & $7.3 \%$ & \\
\hline & & $C D K N 2 A$ & CNA & & & & 0.71 (deletion) \\
\hline & & $E G F R$ & CNA & & & & 68.26 (amplification) \\
\hline & \multirow[t]{2}{*}{ Recurrent } & $E G F R$ & Missense & c. $1793 \mathrm{G}>\mathrm{T}$ & p.Gly598Val & $7.5 \%$ & \\
\hline & & $E G F R$ & CNA & & & & 28.56 (amplification) \\
\hline
\end{tabular}

APC: Adenomatous polyposis coli, CDKN2A: cyclin-dependent kinase inhibitor 2A, CNA: copy number alteration, EGFR: epidermal growth factor receptor, FBXW7: F-box and WD repeat domain-containing 7, PDGFRA: platelet-derived growth factor receptor A, PTEN: phosphatase and tensin homolog, TP53: tumor protein 53.

acquiring mutations in single or multiple genes. Our observations support the previous notions that locally and distally recurrent glioblastomas exhibit different evolutionary patterns, in particular, linear and branching evolutions, respectively, and that the location of tumor recurrence helps predict the evolutionary pattern in glioblastoma.

Concurrent chemoradiation therapy exerts a powerful selective pressure, and chemo- and radio-resistant cell clones contribute to the development of glioblastoma recurrence ( 7 , 40-44). Common ancestral cells are likely to pre-exist in the untreated primary glioblastoma and are positively selected by chemoradiation therapy $(18,41,45-47)$. We observed that single or multiple pathogenic mutations that were not observed in any of the primary glioblastomas, were detected in all of the corresponding distally recurrent glioblastomas, raising the possibility that the residual tumor cells that survive initial treatment may acquire new mutations involving chemo- and radio-resistance, invasion, migration, and adaptation to the new microenvironment $(21,48)$. Further investigations are necessary to clarify the relationship between the development of distal recurrence of glioblastoma and genetic abnormalities in CDKN2A, PDGFRA, EGFR, or FBXW7.

Interestingly, missense mutations of the $E G F R$ gene are only detected in distally recurrent glioblastoma cases, raising the possibility that EGFR mutation may be related to cellular migration and invasion. EGFR mutations have been reported to be involved in the stimulation of tumor angiogenesis, which is essential to metastasis $(49,50)$. In particular, EGFR mutations have shown to significantly increase cellular migration and invasion via promoting angiogenesis in lung carcinoma cells (50). Similarly, missense mutations affecting the extracellular domain of EGFR protein, which are detected in approximately $10 \%$ of glioblastomas, promote tumorigenesis, cellular proliferation, and invasiveness $(9,51,52)$. Further investigations are needed to clarify the effects of missense EGFR mutations on angiogenesis and cellular migration in glioblastoma. 
A limitation of this study involved the lack of analysis of the mutational status of the transcriptional regulator ATRX and telomerase reverse transcriptase promoter, which are frequently detected in glioblastomas, since they were not included in the targeted sequencing panel that we used. We excluded the possibility of de novo glioblastoma in the distally recurrent glioblastoma cases based on the histological similarities and a high concordance in mutational profiles between primary and recurrent tumors. Previous studies have reported that recurrent glioblastomas are derived from a population of cells that are resistant to chemotherapy and radiation therapy $(9,53)$, and glioblastomas contain a subpopulation of highly tumorigenetic glioblastoma stem cells, from which recurrent tumors are thought to derive $(8,47,54)$.

In summary, we investigated the genetic characteristics of glioblastomas using primary and corresponding recurrent tumor tissue samples. We performed targeted sequencing analysis and compared the sequencing data between locally and distally recurrent glioblastoma cases to examine whether there is a difference in the mutational profiles between the two groups. We found that TP53 is the most commonly mutated gene in both the primary and recurrent glioblastomas, followed by PTEN and EGFR. Additionally, we observed that the most common CNAs in primary and recurrent glioblastomas were EGFR amplification and CDKN2A deletion. More importantly, the mutational profiles were completely or partially concordant in 8 of the 10 locally recurrent glioblastoma cases. In contrast, none of the distally recurrent glioblastoma cases showed concordance in the mutational profiles between primary and recurrent tumors. Instead, acquired mutations were detected in all cases of distally recurrent glioblastoma. Our findings support previous notions that locally and distally recurrent glioblastomas exhibit different evolutionary patterns, in particular, linear and branching evolutions, respectively, and that the location of tumor recurrence may help predict the evolutionary patterns in glioblastoma.

\section{Conflicts of Interest}

The Authors have no conflicts of interest to declare.

\section{Author' Contributions}

All the Authors made substantial contributions to the conceptualization and design of the study. This included the acquisition, analysis, curation, and interpretation of the data; drafting, critical revision, and editing of the manuscript for important intellectual content; and the approval of the final version to be published.

\section{Acknowledgements}

This research was supported by a Grant of Translational R\&D Project from the Institute for Bio-Medical Convergence (Incheon St. Mary's Hospital, College of Medicine, The Catholic University of
Korea) and a grant from the National Research Foundation of Korea (NRF) funded by the Korean government (Ministry of Science and ICT) (2018R1C1B5043725). All of the Authors would like to thank Dr. Sung-Im Do (Department of Pathology, Kangbuk Samsung Hospital, Sungkyunkwan University School of Medicine, Seoul, Republic of Korea) for her valuable comments and support.

\section{References}

1 Cloughesy TF, Cavenee WK and Mischel PS: Glioblastoma: from molecular pathology to targeted treatment. Annu Rev Pathol 9: 1-25, 2014. PMID: 23937436. DOI: 10.1146/annurevpathol-011110-130324

2 Aldape K, Zadeh G, Mansouri S, Reifenberger G and von Deimling A: Glioblastoma: pathology, molecular mechanisms and markers. Acta Neuropathol 129: 829-848, 2015. PMID: 25943888. DOI: $10.1007 / \mathrm{s} 00401-015-1432-1$

3 Louis DN, Perry A, Reifenberger G, von Deimling A, FigarellaBranger D, Cavenee WK, Ohgaki H, Wiestler OD, Kleihues P and Ellison DW: The 2016 World Health Organization classification of tumors of the central nervous system: a summary. Acta Neuropathol 131: 803-820, 2016. PMID: 27157931. DOI: $10.1007 / \mathrm{s} 00401-016-1545-1$

4 Z VE, DarAzs B, Paczona V, Dobi A, Reisz Z, Varga Z, Fodor E, CserhAti A, OlAh J, Kis D, Barz OP and HideghEty K: Adaptive radiotherapy for glioblastoma multiforme: the impact on disease outcome. Anticancer Res 40: 4237-4244, 2020. PMID: 32727750 . DOI: 10.21873/anticanres.14425

5 Marchionni A, Palumbo I, Montesi G, Bini V, Zucchetti C, Cenci $\mathrm{N}$, Chiarini P, Saccia S, Aristei C and Lupattelli M: Fractionated stereotactic sequential boost in a selected cohort of glioblastoma patients: a mono-institutional analysis. Anticancer Res 40: 33873393, 2020. PMID: 32487635. DOI: 10.21873/anticanres.14322

6 De Oliveira Rosario LV, Da Rosa BG, Goncalves TL, Matias DIL, Freitas C and Ferrer VP: Glioblastoma factors increase the migration of human brain endothelial cells in vitro by increasing MMP-9/CXCR4 levels. Anticancer Res 40: 2725-2737, 2020. PMID: 32366418. DOI: 10.21873/anticanres.14244

7 Pierscianek D, Ahmadipour Y, Michel A, Chihi M, Oppong MD, Kebir S, Glas M, Stuschke M, Sure U and Jabbarli R: Preoperative survival prediction in patients with glioblastoma by routine inflammatory laboratory parameters. Anticancer Res 40: 11611166, 2020. PMID: 32014969. DOI: 10.21873/anticanres.14058

8 Wilson TA, Karajannis MA and Harter DH: Glioblastoma multiforme: state of the art and future therapeutics. Surg Neurol Int 5: 64, 2014. PMID: 24991467. DOI: 10.4103/2152-7806.132138

9 Wainwright DA, Nigam P, Thaci B, Dey M and Lesniak MS: Recent developments on immunotherapy for brain cancer. Expert Opin Emerg Drugs 17: 181-202, 2012. PMID: 22533851. DOI: $10.1517 / 14728214.2012 .679929$

10 Clarke J, Butowski N and Chang S: Recent advances in therapy for glioblastoma. Arch Neurol 67: 279-283, 2010. PMID: 20212224. DOI: 10.1001/archneurol.2010.5

11 Pasqualetti F, Gonnelli A, Molinari A, Cantarella M, Montrone S, Cristaudo A, Baldaccini D, Mattioni R, Delishaj D, Mazzotti V, Morganti R, Cocuzza P, Fabrini MG, Lombardi G, Ruda R, Soffietti R and Paiar F: Different timing to use bevacizumab in patients with recurrent glioblastoma: early versus delayed administration. Anticancer Res 38: 5877-5881, 2018. PMID: 30275213. DOI: 10.21873/anticanres.12930 
12 Stupp R, Hegi ME, van den Bent MJ, Mason WP, Weller M, Mirimanoff RO, Cairncross JG, European Organisation for R, Treatment of Cancer Brain T, Radiotherapy G and National Cancer Institute of Canada Clinical Trials G: Changing paradigms: an update on the multidisciplinary management of malignant glioma. Oncologist 11: 165-180, 2006. PMID: 16476837. DOI: 10.1634/theoncologist.11-2-165

13 Stupp R, Mason WP, van den Bent MJ, Weller M, Fisher B, Taphoorn MJ, Belanger K, Brandes AA, Marosi C, Bogdahn U, Curschmann J, Janzer RC, Ludwin SK, Gorlia T, Allgeier A, Lacombe D, Cairncross JG, Eisenhauer E, Mirimanoff RO, European Organisation for R, Treatment of Cancer Brain T, Radiotherapy G and National Cancer Institute of Canada Clinical Trials G: Radiotherapy plus concomitant and adjuvant temozolomide for glioblastoma. N Engl J Med 352: 987-996, 2005. PMID: 15758009 . DOI: 10.1056/NEJMoa043330

14 Qin N, Han F, Li L, Ge Y, Lin W, Wang J, Wu L, Zhao G, Deng Y and Zhang J: Deubiquitinating enzyme 4 facilitates chemoresistance in glioblastoma by inhibiting p53 activity. Oncol Lett 17: 958-964, 2019. PMID: 30655854. DOI: 10.3892/ol.2018.9654

15 Scott CB, Scarantino C, Urtasun R, Movsas B, Jones CU, Simpson JR, Fischbach AJ and Curran WJ, Jr.: Validation and predictive power of Radiation Therapy Oncology Group (RTOG) recursive partitioning analysis classes for malignant glioma patients: a report using RTOG 90-06. Int J Radiat Oncol Biol Phys 40: 51-55, 1998. PMID: 9422557. DOI: 10.1016/s03603016(97)00485-9

16 Lau D, Magill ST and Aghi MK: Molecularly targeted therapies for recurrent glioblastoma: current and future targets. Neurosurg Focus 37: E15, 2014. PMID: 25434384. DOI: 10.3171/2014.9. FOCUS14519

17 Weller M, Cloughesy T, Perry JR and Wick W: Standards of care for treatment of recurrent glioblastoma: are we there yet? Neuro Oncol 15: 4-27, 2013. PMID: 23136223. DOI: 10.1093/ neuonc/nos 273

18 Kim H, Zheng S, Amini SS, Virk SM, Mikkelsen T, Brat DJ, Grimsby J, Sougnez C, Muller F, Hu J, Sloan AE, Cohen ML, Van Meir EG, Scarpace L, Laird PW, Weinstein JN, Lander ES, Gabriel S, Getz G, Meyerson M, Chin L, Barnholtz-Sloan JS and Verhaak RG: Whole-genome and multisector exome sequencing of primary and post-treatment glioblastoma reveals patterns of tumor evolution. Genome Res 25: 316-327, 2015. PMID: 25650244. DOI: $10.1101 /$ gr.180612.114

19 Riehmer V, Gietzelt J, Beyer U, Hentschel B, Westphal M, Schackert G, Sabel MC, Radlwimmer B, Pietsch T, Reifenberger G, Weller M, Weber RG, Loeffler M and German Glioma N: Genomic profiling reveals distinctive molecular relapse patterns in IDH1/2 wild-type glioblastoma. Genes Chromosomes Cancer 53: 589-605, 2014. PMID: 24706357. DOI: 10.1002/gcc.22169

20 Wang J, Cazzato E, Ladewig E, Frattini V, Rosenbloom DI, Zairis S, Abate F, Liu Z, Elliott O, Shin YJ, Lee JK, Lee IH, Park WY, Eoli M, Blumberg AJ, Lasorella A, Nam DH, Finocchiaro G, Iavarone A and Rabadan R: Clonal evolution of glioblastoma under therapy. Nat Genet 48: 768-776, 2016. PMID: 27270107. DOI: 10.1038/ng.3590

21 Kim J, Lee IH, Cho HJ, Park CK, Jung YS, Kim Y, Nam SH, Kim BS, Johnson MD, Kong DS, Seol HJ, Lee JI, Joo KM, Yoon Y, Park WY, Lee J, Park PJ and Nam DH: Spatiotemporal evolution of the primary glioblastoma genome. Cancer Cell 28: 318-328, 2015. PMID: 26373279. DOI: 10.1016/j.ccell.2015.07.013
22 Lee JK, Wang J, Sa JK, Ladewig E, Lee HO, Lee IH, Kang HJ, Rosenbloom DS, Camara PG, Liu Z, van Nieuwenhuizen P, Jung SW, Choi SW, Kim J, Chen A, Kim KT, Shin S, Seo YJ, Oh JM, Shin YJ, Park CK, Kong DS, Seol HJ, Blumberg A, Lee JI, Iavarone A, Park WY, Rabadan R and Nam DH: Spatiotemporal genomic architecture informs precision oncology in glioblastoma. Nat Genet 49: 594-599, 2017. PMID: 28263318. DOI: $10.1038 / n g .3806$

23 Louis DN, Ohgaki H, Wiestler OD and Cavenee WK: WHO Classification of Tumours of the Central Nervous System. IARC: Lyon, France, 2016

24 Hovelson DH, McDaniel AS, Cani AK, Johnson B, Rhodes K, Williams PD, Bandla S, Bien G, Choppa P, Hyland F, Gottimukkala R, Liu G, Manivannan M, Schageman J, Ballesteros-Villagrana E, Grasso CS, Quist MJ, Yadati V, Amin A, Siddiqui J, Betz BL, Knudsen KE, Cooney KA, Feng FY, Roh MH, Nelson PS, Liu CJ, Beer DG, Wyngaard P, Chinnaiyan AM, Sadis S, Rhodes DR and Tomlins SA: Development and validation of a scalable next-generation sequencing system for assessing relevant somatic variants in solid tumors. Neoplasia 17: 385-399, 2015. PMID: 25925381. DOI: 10.1016/j.neo.2015.03.004

25 Jeon J, Maeng LS, Bae YJ, Lee EJ, Yoon YC and Yoon N: Comparing clonality between components of combined hepatocellular carcinoma and cholangiocarcinoma by targeted sequencing. Cancer Genomics Proteomics 15: 291-298, 2018. PMID: 29976634. DOI: $10.21873 / \mathrm{cgp} .20087$

$26 \mathrm{Na} \mathrm{K}$ and Kim HS: Clinicopathologic and molecular characteristics of mesonephric adenocarcinoma arising from the uterine body. Am J Surg Pathol 43: 12-25, 2019. PMID: 29189288. DOI: 10.1097/PAS.0000000000000991

27 Kim JY, Kim SH and Kim HS: Promoter methylation downregulates osteoprotegerin expression in ovarian carcinoma. Anticancer Res 39: 2361-2367, 2019. PMID: 31092428. DOI: 10.21873/anticanres.13353

28 Kim JS, Choi YS, Park JH, Yun J, Kim S, Lee JH, Yun BH, Park JH, Seo SK, Cho S, Kim HS and Lee BS: Role of B-cell translocation gene 1 in the pathogenesis of endometriosis. Int J Mol Sci 20: 3372, 2019. PMID: 31324015. DOI: 10.3390/ijms20133372

29 Kim HN, Woo HY, Do SI and Kim HS: Targeted sequencing of tubo-ovarian and peritoneal high-grade serous carcinoma with wild-type p53 immunostaining pattern. In Vivo 33: 1485-1492, 2019. PMID: 31471396 . DOI: 10.21873 /invivo. 11628

30 Jung YY, Woo HY and Kim HS: Targeted genomic sequencing reveals novel TP53 in-frame deletion mutations leading to p53 overexpression in high-grade serous tubo-ovarian carcinoma. Anticancer Res 39: 2883-2889, 2019. PMID: 31177126. DOI: 10.21873/anticanres. 13417

31 Bae GE, Yoon N, Cho EY, Kim HS and Cho SY: Clinicopathological and molecular characteristics of mammary adenoid cystic carcinoma with adipocytic differentiation with emphasis on the identification of a novel BRAF mutation. Anticancer Res 39: 369-374, 2019. PMID: 30591482. DOI: 10.21873/anticanres.13121

32 Sung JY, Jung YY and Kim HS: Clinicopathological characteristics and KRAS mutation status of endometrial mucinous metaplasia and carcinoma. Anticancer Res 38: 27792786, 2018. PMID: 29715099. DOI: 10.21873/anticanres.12521

$33 \mathrm{Na}$ K, Sung JY and Kim HS: TP53 mutation status of tuboovarian and peritoneal high-grade serous carcinoma with a wildtype p53 immunostaining pattern. Anticancer Res 37: 66976703, 2017. PMID: 29187446. DOI: 10.21873/anticanres.12128 
34 Na K, Kim EK, Jang W and Kim HS: CTNNB1 mutations in ovarian microcystic stromal tumors: identification of a novel deletion mutation and the use of pyrosequencing to identify reported point mutation. Anticancer Res 37: 3249-3258, 2017. PMID: 28551672. DOI: 10.21873/anticanres.11688

35 Jung H, Bae GE, Kim HM and Kim HS: Clinicopathological and molecular differences between gastric-type mucinous carcinoma and usual-type endocervical adenocarcinoma of the uterine cervix. Cancer Genomics Proteomics 17: 627-641, 2020. PMID: 32859641. DOI: $10.21873 / \operatorname{cgp} .20219$

36 Yang $\mathrm{H}$ and Wang $\mathrm{K}$ : Genomic variant annotation and prioritization with ANNOVAR and wANNOVAR. Nat Protoc 10: 1556-1566, 2015. PMID: 26379229. DOI: 10.1038/nprot.2015.105

37 Johnson BE, Mazor T, Hong C, Barnes M, Aihara K, McLean CY, Fouse SD, Yamamoto S, Ueda H, Tatsuno K, Asthana S, Jalbert LE, Nelson SJ, Bollen AW, Gustafson WC, Charron E, Weiss WA, Smirnov IV, Song JS, Olshen AB, Cha S, Zhao Y, Moore RA, Mungall AJ, Jones SJM, Hirst M, Marra MA, Saito N, Aburatani H, Mukasa A, Berger MS, Chang SM, Taylor BS and Costello JF: Mutational analysis reveals the origin and therapy-driven evolution of recurrent glioma. Science 343: 189193, 2014. PMID: 24336570. DOI: 10.1126/science.1239947

38 Muscat AM, Wong NC, Drummond KJ, Algar EM, Khasraw M, Verhaak R, Field K, Rosenthal MA and Ashley DM: The evolutionary pattern of mutations in glioblastoma reveals therapy-mediated selection. Oncotarget 9: 7844-7858, 2018. PMID: 29487696. DOI: 10.18632/oncotarget.23541

39 Neilsen BK, Sleightholm R, McComb R, Ramkissoon SH, Ross JS, Corona RJ, Miller VA, Cooke M and Aizenberg MR: Comprehensive genetic alteration profiling in primary and recurrent glioblastoma. J Neurooncol 142: 111-118, 2019. PMID: 30535594. DOI: 10.1007/s11060-018-03070-2

40 Qazi MA, Vora P, Venugopal C, McFarlane N, Subapanditha MK, Murty NK, Hassell JA, Hallett RM and Singh SK: A novel stem cell culture model of recurrent glioblastoma. J Neurooncol 126: 57-67, 2016. PMID: 26498281. DOI: 10.1007/s11060-015-1951-6

41 Orzan F, De Bacco F, Crisafulli G, Pellegatta S, Mussolin B, Siravegna G, D'Ambrosio A, Comoglio PM, Finocchiaro G and Boccaccio C: Genetic evolution of glioblastoma stem-like cells from primary to recurrent tumor. Stem Cells 35: 2218-2228, 2017. PMID: 28895245. DOI: 10.1002/stem.2703

42 Z VE, DarAzs B, Paczona V, Dobi A, Reisz Z, Varga Z, Fodor E, CserhAti A, OlAh J, Kis D, Barz OP and HideghEty K: Adaptive radiotherapy for glioblastoma multiforme - The impact on disease outcome. Anticancer Res 40: 4237-4244, 2020. PMID: 32727750. DOI: 10.21873/anticanres.14425

$43 \mathrm{Kim}$ GW, Lee DH, Yeon SK, Jeon YH, Yoo J, Lee SW and Kwon SH: Temozolomide-resistant glioblastoma depends on HDAC6 activity through regulation of DNA mismatch repair. Anticancer Res 39: 6731-6741, 2019. PMID: 31810938. DOI: 10.21873/anticanres.13888

44 Han HR, Park SA, Ahn S, Jeun SS and Ryu CH: Evaluation of combination treatment effect with TRAIL-secreting mesenchymal stem cells and compound $\mathrm{C}$ against glioblastoma. Anticancer Res 39: 6635-6643, 2019. PMID: 31810928. DOI: 10.21873/anticanres.13878

45 Karsy M, Neil JA, Guan J, Mahan MA, Colman H and Jensen RL: A practical review of prognostic correlations of molecular biomarkers in glioblastoma. Neurosurg Focus 38: E4, 2015. PMID: 25727226. DOI: 10.3171/2015.1.FOCUS14755
46 Gilbertson RJ and Rich JN: Making a tumour's bed: glioblastoma stem cells and the vascular niche. Nat Rev Cancer 7: 733-736, 2007. PMID: 17882276. DOI: $10.1038 / \mathrm{nrc} 2246$

47 Bao S, Wu Q, McLendon RE, Hao Y, Shi Q, Hjelmeland AB, Dewhirst MW, Bigner DD and Rich JN: Glioma stem cells promote radioresistance by preferential activation of the DNA damage response. Nature 444: 756-760, 2006. PMID: 17051156. DOI: $10.1038 /$ nature 05236

48 Fortunato JT, Reys B, Singh P and Pan E: Brainstem glioblastoma multiforme in a patient with NF1. Anticancer Res 38: 4897-4900, 2018. PMID: 30061266. DOI: 10.21873/anticanres.12804

49 Arteaga CL: Epidermal growth factor receptor dependence in human tumors: more than just expression? Oncologist 7(Suppl 4): 31-39, 2002. PMID: 12202786. DOI: 10.1634/theoncologist.7suppl_4-31

50 Hung MS, Chen IC, Lung JH, Lin PY, Li YC and Tsai YH: Epidermal growth factor receptor mutation enhances expression of cadherin-5 in lung cancer cells. PLoS One 11: e0158395, 2016. PMID: 27362942. DOI: 10.1371/journal.pone.0158395

51 Lee JC, Vivanco I, Beroukhim R, Huang JH, Feng WL, DeBiasi RM, Yoshimoto K, King JC, Nghiemphu P, Yuza Y, Xu Q, Greulich H, Thomas RK, Paez JG, Peck TC, Linhart DJ, Glatt KA, Getz G, Onofrio R, Ziaugra L, Levine RL, Gabriel S, Kawaguchi T, O’Neill K, Khan H, Liau LM, Nelson SF, Rao PN, Mischel P, Pieper RO, Cloughesy T, Leahy DJ, Sellers WR, Sawyers CL, Meyerson M and Mellinghoff IK: Epidermal growth factor receptor activation in glioblastoma through novel missense mutations in the extracellular domain. PLoS Med 3: e485, 2006. PMID: 17177598. DOI: 10.1371/journal.pmed.0030485

52 Talasila KM, Soentgerath A, Euskirchen P, Rosland GV, Wang J, Huszthy PC, Prestegarden L, Skaftnesmo KO, Sakariassen PO, Eskilsson E, Stieber D, Keunen O, Brekka N, Moen I, Nigro JM, Vintermyr OK, Lund-Johansen M, Niclou S, Mork SJ, Enger PO, Bjerkvig $\mathrm{R}$ and Miletic H: EGFR wild-type amplification and activation promote invasion and development of glioblastoma independent of angiogenesis. Acta Neuropathol 125: 683-698, 2013. PMID: 23429996. DOI: 10.1007/s00401013-1101-1

53 Murat A, Migliavacca E, Gorlia T, Lambiv WL, Shay T, Hamou MF, de Tribolet N, Regli L, Wick W, Kouwenhoven MC, Hainfellner JA, Heppner FL, Dietrich PY, Zimmer Y, Cairncross JG, Janzer RC, Domany E, Delorenzi M, Stupp R and Hegi ME: Stem cell-related "self-renewal" signature and high epidermal growth factor receptor expression associated with resistance to concomitant chemoradiotherapy in glioblastoma. J Clin Oncol 26: 3015-3024, 2008. PMID: 18565887. DOI: 10.1200/JCO.2007.15. 7164

54 Chen J, Li Y, Yu TS, McKay RM, Burns DK, Kernie SG and Parada LF: A restricted cell population propagates glioblastoma growth after chemotherapy. Nature 488: 522-526, 2012. PMID: 22854781. DOI: $10.1038 /$ nature 11287

Received September 6, 2020

Revised September 23, 2020

Accepted October 1, 2020 